\title{
Unusual venous route of pulmonary artery catheter in a liver transplant recipient: pericardiophrenic or highest intercostal vein? \\ -a case report-
}

\author{
Ji Hyun Park ${ }^{1}$, Ki Choon Sim ${ }^{2}$, Sooho Lee ${ }^{1}$, and Gyu-Sam Hwang ${ }^{1}$ \\ ${ }^{1}$ Department of Anesthesiology and Pain Medicine, Laboratory for Cardiovascular Dynamics, Asan Medical Center, University of \\ Ulsan College of Medicine, ${ }^{2}$ Department of Radiology, Korea University College of Medicine, Anam Hospital, Seoul, Korea
}

We report an extraordinary case in which the venous route for pulmonary artery catheterization was unusual. A 41 yearold woman with an end-stage liver disease underwent a living-donor liver transplantation. After induction of anesthesia, the pulmonary artery catheter was revealed to be advanced into the left brachiocephalic vein and then slipped into another vein that drains into the left brachiocephalic vein. In this case, we assumed that the catheter had most likely slipped into the left pericardiophrenic vein since the catheter follows the left heart border similarly to the route of this vein according to the chest X-ray. Patients with liver cirrhosis develop many collateral vessels and have enlarged veins due to portal hypertension, which makes this vascular route possible. We present this case for anesthesiologists to be aware of the possibilities of unusual venous route due to dilated collateral vessels especially in liver transplant patients. (Korean J Anesthesiol 2014; 67: 57-60)

Key Words: Liver cirrhosis, Pulmonary artery catheterization.

With its introduction in 1970, pulmonary artery catheter (PAC) is frequently used in a perioperative setting for the aid of management in hemodynamically unstable patients. Moreover, PAC is performed in most of the patients undergoing liver transplantation to monitor several hemodynamic parameters which are helpful in managing massive fluid shifts. However, complications concerning PAC insertion have been reported widely [1].
Complications regarding PAC insertion include arrhythmia, complete heart block, infections, catheter knotting, and pulmonary artery rupture [2]. In addition, inadvertent insertion of the catheter into unwanted position due to aberrant venous anatomy may be another complication which can end up in deleterious events.

In liver cirrhosis patients with esophageal varix, dilatation

Received: May 31, 2013. Revised: 1st, July 3, 2013; 2nd, July 4, 2013. Accepted: July 5, 2013.

Corresponding author: Gyu-Sam Hwang, M.D., Ph.D., Department of Anesthesiology and Pain Medicine, Laboratory for Cardiovascular Dynamics, Asan Medical Center, University of Ulsan College of Medicine, 88, Olympic-ro 43-gil, Songpa-gu, Seoul 138-736, Korea. Tel: 82-23010-3868, Fax: 82-2-470-1363, E-mail: kshwang@amc.seoul.kr

(C)This is an open-access article distributed under the terms of the Creative Commons Attribution Non-Commercial License (http:// creativecommons.org/licenses/by-nc/3.0/), which permits unrestricted non-commercial use, distribution, and reproduction in any medium, provided the original work is properly cited. 
of collateral vessels is very common. Thus, venous anatomy of these patients tends to be quite different from normal patients in which can result in malposition of central venous catheterization. Here, we report an extraordinary case in which the venous route for the insertion of PAC in a liver transplantation recipient was very unusual.

\section{Case Report}

A 41-year-old woman diagnosed with hepatitis B-related liver cirrhosis was scheduled for elective living-donor liver transplantation. The patient's height and weight were $157 \mathrm{~cm}$ and $58 \mathrm{~kg}$, respectively. Her Child-Pugh classification grade was A with a model for end-stage liver disease (MELD) score of 8 . She had no specific medical history. Her laboratory findings included hemoglobin $9.6 \mathrm{~g} / \mathrm{dl}$, platelet $47,000 / \mathrm{mm}^{3}$, INR 1.19 , albumin $3.7 \mathrm{~g} / \mathrm{dl}$, and total bilirubin $0.7 \mathrm{mg} / \mathrm{dl}$. Her preoperative chest $\mathrm{X}$-ray revealed no active lung lesion. The dynamic liver CT scan showed liver cirrhosis with portal hypertension. Esophagogastroduodenoscopy revealed esophageal varix which was treated by propranolol.

The patient did not take any premedication before surgery. Upon arrival in the operating room, routine monitoring including five-lead electrocardiogram, non-invasive blood pressure, and pulse oximetry was started. Her blood pressure was 115/75 mmHg, heart rate was 65 beats/min, and the oxygen saturation was $100 \%$. Before induction of anesthesia, the right radial artery was cannulated to monitor continuous arterial pressure. The anesthesia was induced using thiopental $250 \mathrm{mg}$, fentanyl $100 \mu \mathrm{g}$, and midazolam $5 \mathrm{mg}$. Vecuronium $10 \mathrm{mg}$ was injected for the ease of endotracheal intubation. The patient was aseptically prepared and draped for central venous catheterization. A 7.5- Fr pulmonary artery catheter (Swan Ganz CCOmbo V; Edwards Life- sciences, Irvine, CA) was inserted via a 9.0- Fr introducer (AVA HF; Edwards Lifesciences) through the right subclavian vein. The right subclavian vein was chosen because an 11.5 Fr. twolumen central venous catheter (Mahurkar, Covidien, Mansfield, MA, USA) had been inserted in the right internal jugular vein (IJV) preoperatively for the purpose of therapeutic plasmapheresis owing to $\mathrm{ABO}$ incompatible transplantation. The tip of the PAC was ballooned and advanced through the introducer without resistance. While observing the waveforms of the PAC, the pressure wave on the monitor continuously showed a form of central venous pressure although the catheter was nearly $40 \mathrm{~cm}$ inside the vein. The catheter was pulled back outside the sheath for reinsertion. Further attempts were made, but the waveform did not change to a right ventricular pressure waveform. The vital signs were stable and no arrhythmia was present. Thus, to avoid any complications, an anteroposterior chest X-ray was taken when the catheter was about $40 \mathrm{~cm}$ inside the vein. The X-ray revealed that the PAC had erroneously advanced straight into the left brachiocephalic vein and turned to its opposite direction to slip into another vein that drains into the left brachiocephalic vein (Fig. 1A). We were convinced that the catheter was not placed extravascularly and was therefore not resting on the mediastinum or in the pleural space, as confirmed by stable vital signs with freely regurgitating blood and intact lung parenchyma in the chest X-ray. Also, a venous anomaly such as bilateral superior vena cava was ruled out by a preoperative chest CT scan. We assumed that the catheter had most likely slipped through the left pericardiophrenic vein from the left brachiocephalic vein since the catheter follows the left heart border similarly to the route of this vein. We cautiously reviewed the chest CT once more with the radiologist and noticed that there were branches stemming out from the left brachiocephalic vein, which appeared to be the left pericardiophrenic vein (Fig. 1B).
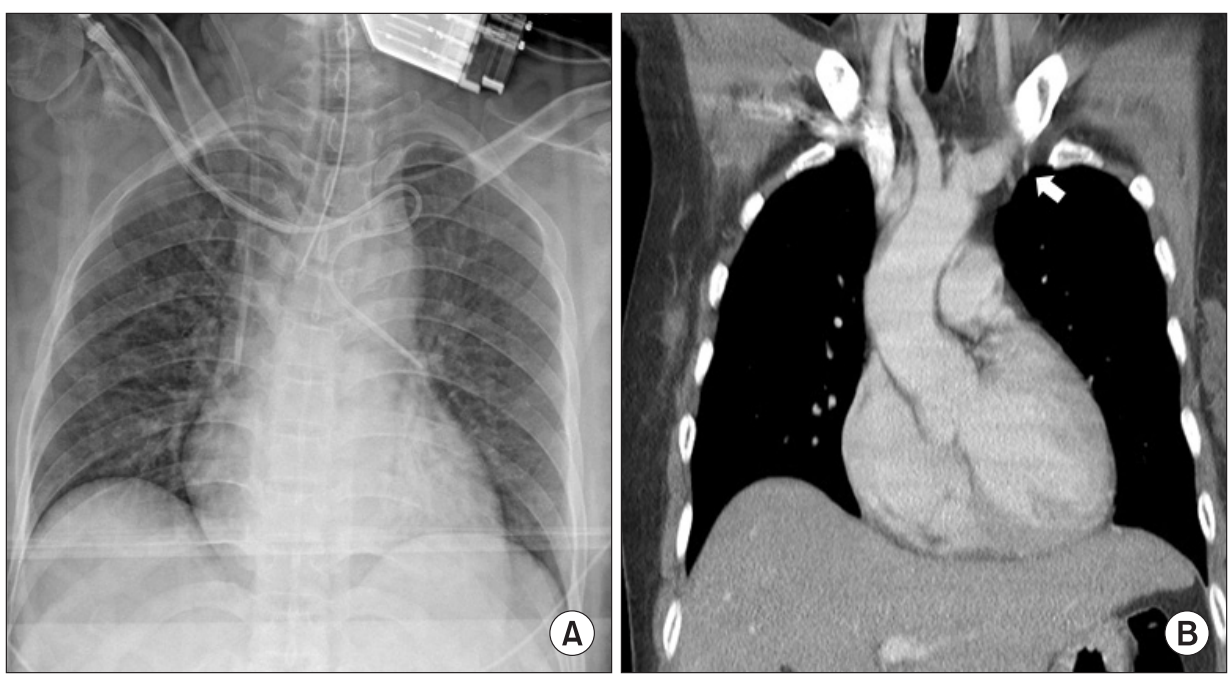

Fig. 1. (A) Chest X-ray shows malposition of the pulmonary artery catheter inserted from the right subclavian vein, which follows along the left heart border. (B) CT scan reveals enlarged branches (arrow) that drain into the left brachiocephalic vein, suggesting either the pericardiophrenic vein or the highest intercostal vein. 
The surgery was processed without the PAC insertion. Fortunately, the surgery was finished uneventfully and the patient had discharged from the hospital after 17 days.

\section{Discussion}

PAC is performed in most of the patients undergoing liver transplantation to monitor central venous pressure, pulmonary artery pressure, cardiac output, systemic venous resistance, pulmonary vascular resistance, pulmonary capillary wedge pressure, and mixed venous oxygen saturation. These parameters are useful in managing massive fluid shifts that occur in liver transplantation. However, this catheterization is very invasive and comes with several complications that may threat the patient's life. These severe complications include dysrrhythmia ( 62.7\%), tricuspid regurgitation $(\sim 17 \%)$, complete heart block $(\sim 8.5 \%)$, pulmonary artery rupture $(\sim 1.5 \%)$, pulmonary infarction $(\sim 5 \%)$, and death $(\sim 1.5 \%)[2,3]$.

In our case, the venous route for pulmonary artery catheter was unusual. We assumed that the catheter had most likely slipped through the left pericardiophrenic vein from the left brachiocephalic vein since the catheter follows the left heart border similarly to the route of this vein [4]. The ostium of the left pericardiophrenic vein is usually in the left brachiocephalic vein. Inferiorly, the right and left pericardiophrenic veins join the inferior phrenic veins and branch to continue on to inferior vena cava, hepatic veins, or left renal veins [5].We suspected that the catheter had been placed in the left pericardiophrenic vein which has the highest possibility among other veins such as internal mammary vein or highest intercostal vein which all drain into the left subclavian vein [6]. Also, one possibility of the reason why the PAC catheter had turned its direction oppositely may be due to venous valve that had interrupted the advancement. However, the possibility of this branch to be the highest intercostal vein or the internal mammary vein cannot be excluded since neither lateral X-ray nor contrast imaging was performed [7]. Angiography would have confirmed the exact position of the misplaced catheter.

Usually, right IJV is preferred over left IJV since the right IJV has the shortest route to the right atrium, and the angle between the right IJV and the brachiocephalic vein is less that those with the left IJV. Other sites such as right subclavian vein or left IJV have shown more complications regarding insertion of central venous catheterization [8]. However, our patient already had a central venous catheter inserted in the right internal jugular vein. Thus, we chose the right subclavian vein for the insertion of the pulmonary artery catheter. While cannulating the right subclavian vein with the PAC sheath, the already inserted IJV catheter may have blocked the PAC and would have misled the PAC straight into the left brachiocephalic vein instead of guiding it down the superior vena cava. To the best of our knowledge, this unusual venous route of pulmonary artery catheterization cannulated from the right side has never been previously reported in the literature, although cases of cannulation from the left IJV with inadvertent placement of the pulmonary artery catheter into left pericardiophrenic vein have been published [9]. In another report, cannulation of central venous catheter in the left pericardiophrenic vein had led to cardiac tamponade due to vessel rupture [10].

Patients with liver cirrhosis develop many collateral vessels with enlarged veins due to portal hypertension, which makes this vascular route possible [11]. Portal hypertension leads to changes in the systemic and portosystemic collateral circulation which results in engorged veins [12]. Thus, patients with portal hypertension depict different venous anatomy which may affect the outcome of the cannulation of central veins. There was a debate regarding whether the cannulation was in the persistent left superior vena cava or the pericardiophrenic vein in a liver transplant patient [13].We agree with the suggestions by Verniquet et al. [14] of the possibilities of having cannulated the left pericardiophrenic vein, as with our case.

In conclusion, in portal hypertension patients with a history of esophageal varix, dilated collateral vessels should always be considered during cannulation of central lines which is a very invasive procedure. Anesthesiologists should be aware of the chances of unusual routes of the pulmonary artery catheter in these patients.

\section{Acknowledgments}

This case is listed on "Out of the blue e-letter" of British Journal of Anaesthesia (online).

BJA editorial office officially permitted to publish in the other journal since it has been confirmed that the e-letter would not appear in the future issues.

We declare no conflict of interest.

\section{References}

1. Bernard GR, Sopko G, Cerra F, Demling R, Edmunds H, Kaplan S, et al. Pulmonary artery catheterization and clinical outcomes: National Heart, Lung, and Blood Institute and Food and Drug Administration Workshop Report. Consensus Statement. JAMA 2000; 283: $2568-72$.

2. Slung HB, Scher KS. Complications of the Swan-Ganz catheter. World J Surg 1984; 8: 76-81. 
3. Practice guidelines for pulmonary artery catheterization: an updated report by the American Society of Anesthesiologists Task Force on Pulmonary Artery Catheterization. Anesthesiology 2003; 99: 988-1014.

4. Krishnan A, Cacciarelli A,Gibson D. Unusual complication of peripherally inserted central venous catheter placement: the left pericardiophrenic vein. Pediatr Radiol 2004; 34: 180-1.

5. Godwin JD, Chen JT. Thoracic venous anatomy. AJR Am J Roentgenol 1986; 147: 674-84.

6. Sandroni C, Pirronti T, Tortora F, Santangelo S, Rinaldi P, Antonelli M. Unusual central venous catheter malposition into the left internal mammary vein: a case report. Intensive Care Med 2003; 29: 2338-9.

7. Moskal TL, Ray CE Jr. Left mediastinal central line malposition--a case report. Angiology 1999; 50: 349-53.

8. Pikwer A, Bååth L, Davidson B, Perstoft I, Akeson J. The incidence and risk of central venous catheter malpositioning: a prospective cohort study in 1619 patients. Anaesth Intensive Care 2008; 36: 30-7.

9. McLellan BA, Jerman MR, French WJ, Criley JM, Pelikan PC. Inadvertent Swan-Ganz catheter placement in the left pericardiophrenic vein. Cathet Cardiovasc Diagn 1989; 16: 173-5.

10. van Haeften TW, van Pampus EC, Boot H, Strack van Schijndel RJ, Thijs LG. Cardiac tamponade from misplaced central venous line in pericardiophrenic vein. Arch Intern Med 1988; 148: 1649-50.

11. Widrich WC, Srinivasan M, Semine MC, Robbins AH. Collateral pathways of the left gastric vein in portal hypertension. AJR Am J Roentgenol 1984; 142: 375-82.

12. Cichoz-Lach H, Celiński K, Słomka M, Kasztelan-Szczerbińska B. Pathophysiology of portal hypertension. J Physiol Pharmacol $2008 ; 59$ Suppl 2: 231-8.

13. Schreiber KL, Matsusaki T, Bane BC, Bermudez CA, Hilmi IA, Sakai T. Accidental insertion of a percutaneous venovenous cannula into the persistent left superior vena cava of a patient undergoing liver transplantation. Can J Anaesth 2011; 58: 646-9.

14. Verniquet A, Kakel R. Cannulation of a persistent left superior vena cava or a pericardiophrenic vein? Can J Anaesth 2012; 59: 232-3. 